\title{
A High Temperature Lithium Metal-Air Primary Battery Based on Solid Electrolytes and Molten Salt
}

\author{
Geoff McConohy*1, Dokyum Kim², Joon-Hyung Lee² \\ ${ }^{1}$ Department of Materials Science and Engineering, Stanford University, California, USA \\ ${ }^{2}$ School of Materials Science and Engineering, Kyungpook National University, Daegu, South Korea \\ *Corresponding author: mcconohy@stanford.edu
}

November 3, 2021

\begin{abstract}
Developing metal-oxygen batteries with a high specific energy (gravimetric energy density) is a significant challenge due to the highly reactive nature of active materials used as the negative electrode, such as $\mathrm{Li}, \mathrm{Al}$, or $\mathrm{Mg}$. In addition, the metal-oxide discharge products are highly stable and passivating to many oxygen-reduction catalysts. Here we present an alterative way of utilizing the high specific energy lithium metal-oxygen reaction by combining both cation and anion transport in a single device, operated at $550^{\circ} \mathrm{C}$. To do this, we combined a $\mathrm{Li}_{6.4} \mathrm{La}_{2.8} \mathrm{Al}_{0.2} \mathrm{Zr}_{1.4} \mathrm{Ta}_{0.6} \mathrm{O}_{12}$ (LLZO) cation solid electrolyte, yttria stabilized zirconia oxygen ion conductor, and $\mathrm{KCl}-\mathrm{LiCl}$ eutectic salt as an interlayer between the two solid electrolytes. We find that the constructed battery shows an open circuit voltage consistent with the thermodynamic value predicted for the $\mathrm{Li}-\mathrm{O}_{2}$ reaction at $550^{\circ} \mathrm{C}$. Furthermore, we found that the cell could be discharged at $20 \mathrm{~mA}$, showing no significant passivation of the reaction until all of the lithium metal was depleted. However, we were unable to re-deposit the lithium metal electrochemically, possibly due to parasitic reduction of the LLZO tube upon charging. This work presents a unique device which may inspire other high temperature electrochemical devices in the field.
\end{abstract}

\section{Introduction}

Metal-air (or metal oxygen) batteries have been a research topic for many decades with the hope of creating high specific energy batteries. However, most of this research is conducted at room temperatures, where a number of challenges remain. For aqueous metal-oxygen batteries, such as the aluminum-air primary cell, corrosion reactions between the aqueous electrolyte and negative electrode significantly decrease available capacity of the device. While this problem can be mitigated by using high purity metals, this significantly increases cost [1]. Non-aqueous electrolytes have been explored for a number of different metal-air battery systems, particularly for the lithiumair system, but the insoluble nature of metal oxide discharge products results in passivation of the air electrode [2]. Furthermore, the catalysts used in non-aqueous lithium-air batteries are sensitive to atmospheric contaminants such as water and $\mathrm{CO}_{2}$. Some have proposed to enclose a metal-air battery in a sealed pressure vessel to mitigate the contaminant problem. However, in this case the energy density is significantly limited and may not be competitive compared to even current lithium-ion batteries [3].

With such a large array of problems associated with room temperature metal-air batteries, interest has increased in elevated temperature metal-air batteries. For example, lithium-air batteries have been reported to function at temperatures of $\sim 100^{\circ} \mathrm{C}$ using a molten nitrate electrolyte [4-5]. Another approach, the focus of this article, is to use a solid oxide fuel cell-type framework to allow for oxygen ions as the charge carrier, rather than metal cations, as shown in Figure 1. This framework is termed "solid oxide metal-air battery". In this architecture, oxygen ions transport through a solid electrolyte and combine with metal cations which have donated electrons to the external circuit. The resulting metal oxide is deposited at the interface between the metal and the solid electrolyte. However, as the metal oxide layer grows, there could be transport limitations either due to oxygen anion or metal cation transport though the growth front. 


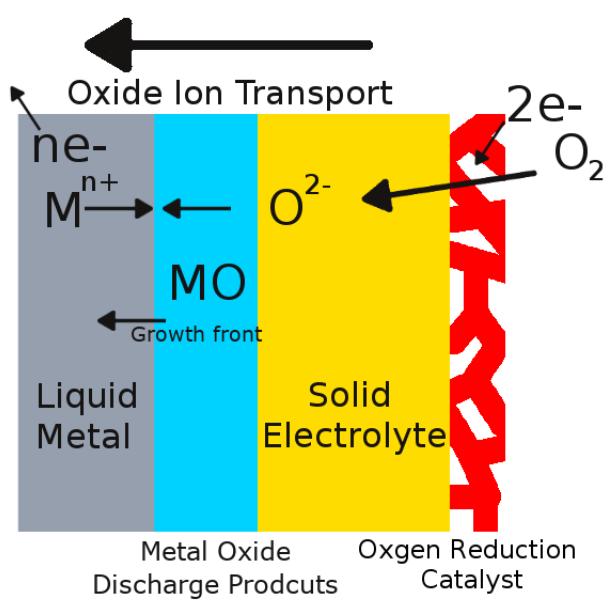

Figure 1: Schematic of discharge reactions in a solid oxide metal-air battery

Researchers have recently found that low specific energy metals, such as tin or antimony, can successfully cycle in solid oxide metal air battery systems. Otaegui et. al have shown that molten tin at $800^{\circ} \mathrm{C}$ can be used as fuel in a solid oxide battery and cycled for 4500 cycles with high coulombic efficiency [6]. However, they could only access 10-20 microns of fuel, and used low power densities of $\sim 10 \mathrm{~mW} / \mathrm{cm} 2$. Javadekar et. al showed that liquid antimony at $700^{\circ} \mathrm{C}$ could also effectively be used in this type of architecture. In addition, the antimony-oxide discharge product is also a liquid at these temperatures. By mechanically mixing the liquid oxide mixture during cycling, they can remove the interfacial oxide, leading to much higher power densities of $240 \mathrm{~mW} / \mathrm{cm} 2$ and conversion of $>95 \%$ of the $\mathrm{Sb}$ to $\mathrm{Sb}_{2} \mathrm{O}_{3}$ [7].

Only one article has been published which uses a high energy density metal in conduction with a molten salt and an oxide ion solid electrolyte [8]. This battery uses aluminum as the storage medium at $800^{\circ} \mathrm{C}$, and mixes cryolite into the electrode to lower the melting point of the oxide, as is done with commercial aluminum smelters. However, the resulting open circuit voltage of the cell was only half the theoretical, and the power densities were only $\sim 30 \mathrm{~mW} / \mathrm{cm} 2$.

Finally, the first lithium-based oxygen battery was operated at high temperatures [9]. The negative electrode was made from a porous alloy of $\mathrm{Li}, \mathrm{Si}$, and $\mathrm{Fe}$ and the electrolyte was a hybrid of molten $\mathrm{LiF}-\mathrm{LiCl}-\mathrm{Li}_{2} \mathrm{O}$ (lithium ion conductor) and a $\mathrm{CaO}$ doped $\mathrm{ZrO}_{2}$ (oxygen ion conductor). It showed an average voltage of $2.2 \mathrm{~V}$, changing with the state of lithiation of the negative electrode. The peak areal power density on discharge was about $200 \mathrm{~mW} / \mathrm{cm}^{2}$ based on the area of the negative electrode. While the electrochemical performance of this device was quite good, the energy density of the device is quite low, due to the use of the Li-Fe-Si alloy, which both lowers the average voltage and also increases the mass of the active components.

The use of a higher specific energy material would be advantageous for the solid oxide metal-air battery systems. However, the lighter elements such as sodium, magnesium, lithium and aluminum are much more reducing than the materials studied thus far in the literature. This makes the use of oxide ion conductors such as yttria stabilized zirconia (YSZ) very challenging because they are not chemically (thermodynamically) stable to these higher specific energy materials. This work seeks to address some of the challenges with high temperature lithium-air batteries, by employing additional materials to help suppress the reductive nature of lithium metal. 

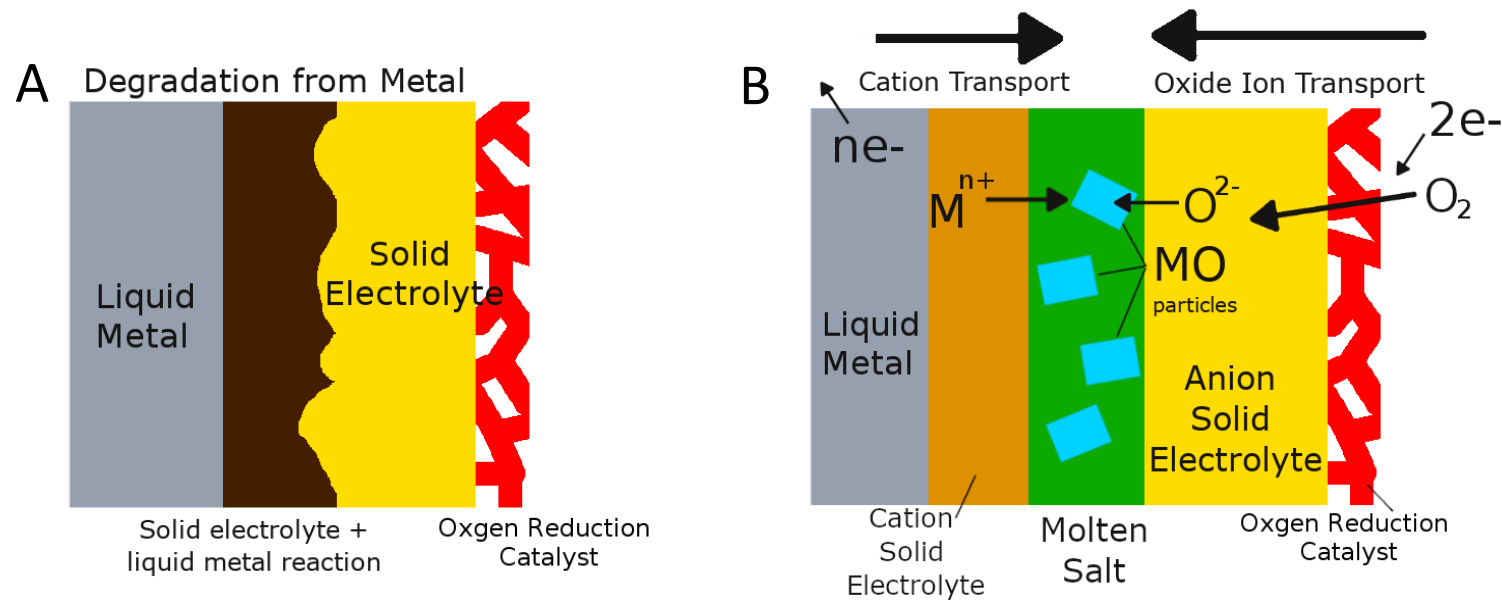

Figure 2: (a) schematic of the reactive process between liquid metals and oxide solid electrolytes. (b) schematic showing the use of a cation solid electrolyte (brown) and molten salt (green) to protect the oxide solid electrolyte and facilitate the deposition of particles of metal oxide (blue) as discharge products.

\section{Dual solid electrolyte cell architecture}

As noted above, one of the major challenges associated with solid-oxide metal-air batteries is that the oxygen ion conductor is typically not chemically stable to molten metals with high energy density. This results in degradation at the liquid-metal, oxygen-ion solid electrolyte interface, as shown in Figure 2a.

In addition to the chemical reactivity issue, most metal oxides have poor ionic conductivity for both cations and anions. Therefore, as the discharge products build up in a solid oxide metal air battery (as shown in Figure 1), there will likely be passivation of the oxide-ion solid electrolyte. In order to solve this issue, and the chemical stability problem, a more complex scheme is required. Naively, the addition of a molten salt between the liquid metal and the anion solid electrolyte could solve both of these issues: the salt prevents contact between the liquid metal and the oxide-ion solid electrolyte, and also provides some solubility to the metal oxide discharge products to dislodge them from the interface. However, molten metals are often slightly soluble in molten salts [10], which means that the salt will not be able to protect the oxide-ion electrolyte from reactions with the molten metal. To prevent the dissolution of molten metal, an additional solid electrolyte is placed in between the metal and molten salt. This is shown schematically in Figure $2 \mathrm{~b}$.

For this scheme to be effective, the molten salt must contain a high concentration of metal cations or oxygen anions to ensure a low resistance. Luckily, many high energy density metals form molten salts which can serve as low resistance layers for cation transport. In addition, the cation solid electrolyte should also be chemically stable to the molten metal. This presents a significant challenge, but it may be easier to design a stable liquid metal-cation conductor interface than a stable molten metal- oxide-ion conductor interface.

Material selection and electrochemical reactions for $\mathrm{Li}^{\mathrm{i}} \mathrm{O}_{2}$ cell

In this work, we examined the possibility of a Li- $\mathrm{O}_{2}$ based battery. The reason for a lithiumbased battery instead of magnesium or aluminum is because of the availability of cation solid electrolytes for lithium ions, and because of the instabilities of aluminum and magnesium chloride salts when exposed to air. Due to these considerations, we chose to use $\mathrm{Li}_{6.4} \mathrm{La}_{2.8} \mathrm{Al}_{0.2} \mathrm{Zr}_{1.4} \mathrm{Ta}_{0.6} \mathrm{O}_{12}$ 
(LLZO) as the lithium cation solid electrolyte. For the molten salt, we chose to use a eutectic mixture of $\mathrm{KCl}-\mathrm{LiCl}$ due to its relatively low eutectic melting point of $\sim 350^{\circ} \mathrm{C}$. Interestingly, molten lithium is slightly soluble in molten $\mathrm{LiCl}-\mathrm{KCl}$ [10], and causes the molten salt to become electronically conductive, which might lead to reduction of the oxide solid electrolyte. This highlights the importance of the combination of molten salt and cation solid electrolyte to enable the use of molten lithium electrodes. On the positive electrode, YSZ was chosen for the oxygen cation conductor due to its good conductivity and commercial availability. Porous platinum was used for the oxygen catalyst because of the ease of coating onto the curved surface of the YSZ.

In the charged state, the molten lithium metal is contained in the LLZO tube, and the molten salt electrolyte contains a low concentration of oxide ions, as shown in Figure 3A. As the cell discharges, lithium ions move from the negative electrode into the LLZO tube, and then into the molten salt electrolyte, while the electron is discharged around the external circuit. On the positive electrode side, oxygen gas is oxidized from $\mathrm{O}_{2}$ to $20^{-2}$ where the oxide ions reside in the YSZ tube. The oxide ions transport through the YSZ tube and are deposited into the molten salt electrolyte. In low concentrations, the oxide ions are soluble in the molten salt. However, once the solubility limit is reached, the oxide ions combine with lithium ions to form lithium oxide precipitate. In the fully discharged state, solid lithium oxide exists in the molten salt, with no lithium metal inside the LLZO tube. The lithium and oxide ion transport are outlined in Table 1 and Figure 3B, showing the different electrochemical reactions occurring at each interface.

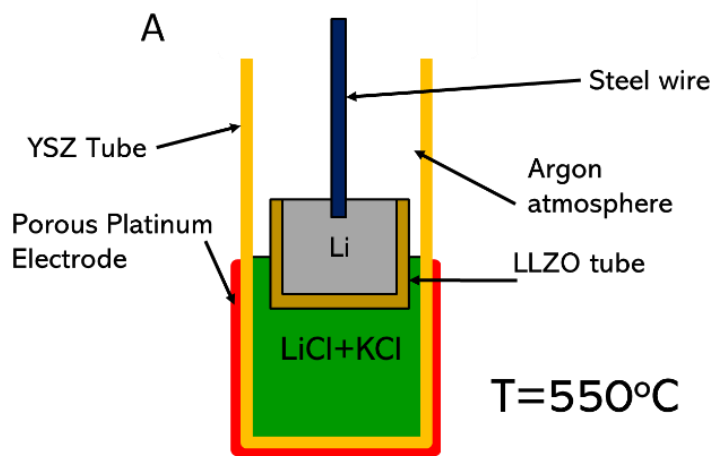

B

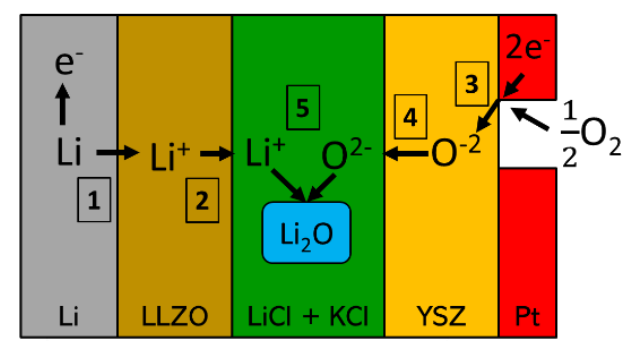

Figure 3: (a) A schematic of the high temperature electrochemical cell in the charged state. (b) Schematic of electrochemical reactions occurring in cell, with numeric labels corresponding to Table 1.

Table 1: Electrochemical Reactions in the Solid Oxide Lithium-Air Cell

\begin{tabular}{lcc}
\hline Negative Electrode-LLZO interface: & $\mathrm{Li}_{\mathrm{liq}} \rightarrow \mathrm{Li}_{\mathrm{LLZ}}^{+}+\mathrm{e}^{-}$ & (1) \\
LLZO-molten salt interface & $\mathrm{Li}_{\mathrm{LLZ}}^{+} \rightarrow \mathrm{Li}_{\text {sol }}^{+}$ & (2) \\
Positive Electrode: & $\mathrm{O}_{2 \text { gas }}+4 \mathrm{e}^{-} \rightarrow 2 \mathrm{O}_{\mathrm{YSZ}}^{-2}$ & (3) \\
Salt-YSZ interface: & $\mathrm{O}_{\mathrm{YSZ}}^{-2} \rightarrow \mathrm{O}_{\mathrm{sol}}^{-2}$ & $(4)$ \\
$\begin{array}{l}\text { Precipitation Reaction in molten salt } \\
\text { (if oxide ion is above solubility limit): }\end{array}$ & $2 \mathrm{Li}_{\text {sol }}^{+}+\mathrm{O}_{\text {sol }}^{-2} \rightarrow \mathrm{Li}_{2} \mathrm{O}_{(\mathrm{s})}$ & $(5)$ \\
\hline Total & $4 \mathrm{Li}_{\text {liq }}+\mathrm{O}_{2 \text { gas }} \rightarrow \mathrm{Li}_{2} \mathrm{O}_{(\mathrm{s})}$ & $(6)$ \\
\hline $\begin{array}{l}\text { Predicted open circuit voltage (OCV) at } \\
550^{\circ} \mathrm{C} \text { from thermochemical data }\end{array}$ & $2.56 \mathrm{~V}$ & \\
\hline
\end{tabular}

The subscripts "sol", "YSZ", and "LLZ", indicate species solvated in the molten salt mixture, YSZ solid electrolyte, or LLZATO solid electrolyte, respectively. 


\section{Experimental}

\section{LLZO Tube Synthesis and Fabrication}

$\mathrm{Li}_{6.4} \mathrm{La}_{2.8} \mathrm{Al}_{0.2} \mathrm{Zr}_{1.4} \mathrm{Ta}_{0.6} \mathrm{O}_{12}$ (LLZO) was synthesized via bulk ceramic processing methods. $\mathrm{Li}_{2} \mathrm{CO}_{3}$ (High purity chemicals JPN 4N), $\mathrm{La}_{2} \mathrm{O}_{3}$ (Alfa Aesar USA 4N), $\mathrm{ZrO}_{2}$ (1Micron) (Alfa Aesar USA $3 \mathrm{~N}$ ), $\mathrm{Ta}_{2} \mathrm{O}_{5}$ (0.5Micron) (High purity chemicals JPN $3 \mathrm{~N}$ ), and $\mathrm{Al}_{2} \mathrm{O}_{3}$ (TAMEI JPN 4N) were ball milled for 24 hours in ethyl alcohol, and then dried at $80^{\circ} \mathrm{C}$ for 24 hours. $10 \%$ by weight excess of $\mathrm{Li}_{2} \mathrm{CO}_{3}$ was used to compensate for lithium loss during calcination and sintering. The mixture was then calcined at $950^{\circ} \mathrm{C}$ for 10 hours, followed by attrition milling in isopropyl alcohol for 2 hours at 450 rpm. All milling used zirconia balls. The calcined and milled powder was then cold pressed uniaxially under 2 tons of force for 5 minutes. It was pressed into a tube shape with one end closed. The tube dimensions were $5 \mathrm{~mm}$ outside diameter, $3 \mathrm{~mm}$ inside diameter, and $2.5 \mathrm{~cm}$ long. After pressing, the tube was sintered at $1200^{\circ} \mathrm{C}$ for 4 hours. The tube was covered with the calcined powder to help to prevent lithium loss. The density of the sintered ceramic was measured to be $93 \%$.

\section{Cell Design}

The cell design is similar to that published in 1987 by Semkow [9]. However, in order to enable the use of a lithium metal negative electrode, we used a tube, closed on one end, made of $\mathrm{Li}_{6.4} \mathrm{La}_{2.8} \mathrm{Al}_{0.2} \mathrm{Zr}_{1.4} \mathrm{Ta}_{0.6} \mathrm{O}_{12}$ (LLZO) in order to contain the molten lithium at high temperatures. A stainless-steel wire was used for the current collector to the molten lithium. The cell utilized an equimolar LiCl-KCl molten salt (Sigma) to provide sufficient oxide and lithium-ion transport and act as a solvent for the discharge products. An oxide solid electrolyte was used to both provide the housing for the cell, and also transport oxide ions from the positive electrode to the molten salt. The oxide solid electrolyte was made of $\mathrm{ZrO}_{2}$ with $8 \% \mathrm{Y}_{2} \mathrm{O}_{3}$ (YSZ, McDanel Ceramics). The YSZ tube is $0.95 \mathrm{~cm}$ outside diameter, and $0.64 \mathrm{~cm}$ inside diameter. The positive electrode was made of porous Pt (Heraeus) and a silver wire was adhered to the platinum to establish an electrical connection. The porous Pt was coated on a surface area of about $10 \mathrm{~cm}^{2}$. YSZ tube was connected to a Swagelok ultra-torr fitting to allow for argon gas to be applied to the cell, preventing oxidation of the lithium. A schematic of the cell is shown in Figure 3A.

\section{Cell Assembly}

To assemble the cell, $\sim 0.2$ grams of a $50 \mathrm{wt} \%$ mixture of $\mathrm{LiCl}$ and $\mathrm{KCl}$ was first dried on a hot plate at $\sim 150^{\circ} \mathrm{C}$ for 30 minutes. Then the mixture was loaded into a YSZ tube. Separately, lithium metal $(\sim 10 \mathrm{mg})$ was loaded into a smaller LLZO tube along with a stainless-steel current collector inside of an argon glovebox. The LLZO tube with lithium inside was removed from the glovebox, quickly inserted into the YSZ tube and pressurized $(<1 \mathrm{psi})$ with argon gas to prevent oxidation of the lithium. To ensure the salt was completely dry, the assembled cell was heated to $130^{\circ} \mathrm{C}$ for $\sim 20$ hours under argon atmosphere before the test began. Even small amounts of water present in the salt could cause the lithium metal to completely oxidize at higher temperatures. After the drying step, the cell temperature was increased to $550^{\circ} \mathrm{C}$ and maintained at a constant temperature for the test. The geometry of the assembled cell is displayed in Figure 3.

\section{Results and Discussion}

\section{Electrochemical discharge of battery}

Upon first heating the cell to $550^{\circ} \mathrm{C}$, we find the open circuit voltage (OCV) to be $\sim 2.7 \mathrm{~V}$. To understand this potential, we must examine the reactions which occur at each interface of the cell. The open circuit voltage of the cell is determined by the reactions listed in Table 1. 
The concentration of the oxide ion in the molten salt is quite low upon first assembly of the cell. This means that, before the lithium oxide reaches a saturation in the electrolyte, the open circuit voltage will be greater than the value in Table 1, due to the effect of mixing entropy of the $\mathrm{Li}_{2} \mathrm{O}$ in the molten salt. However, after reaching the solubility of $\mathrm{Li}_{2} \mathrm{O}$ in the $\mathrm{LiCl}-\mathrm{KCl}$ mixture (about $1 \mathrm{~mol} \%$ at $550^{\circ} \mathrm{C}[11]$ ) the open circuit voltage remains fixed at $2.56 \mathrm{~V}$. Interestingly based on the amount of lithium oxide discharged between the initial state and the state which reaches $2.56 \mathrm{~V}$, we would not expect the solubility limit to be reached. One possible rationalization for this observation is that other oxide ions have been dissolved into the solution from the YSZ and LLZO tubes, making precipitation of $\mathrm{Li}_{2} \mathrm{O}$ favorable even at low amounts of charge passed.

Figure 4 shows the discharge of the cell at $20 \mathrm{~mA}$, with periodic rests to measure the open circuit voltage. From this result, it is clear that the open circuit voltage stays constant over a wide compositional change in the system. The constant open circuit voltage supports that the reaction being performed upon discharge is indeed the lithium-oxygen reaction shown in Table 1. However, more direct evidence is needed to confirm the true discharge reaction.

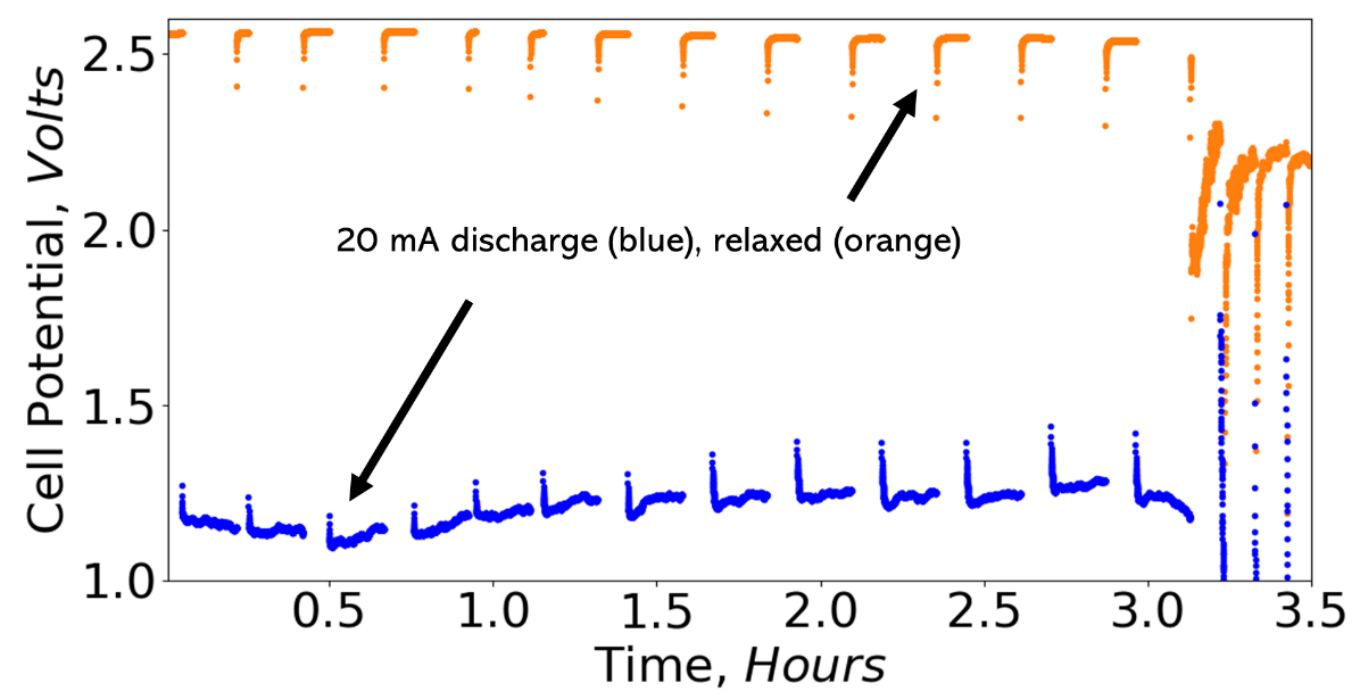

Figure 4: Discharge electrochemistry of the lithium-oxygen cell at a constant current of $20 \mathrm{~mA}$.

We observe that the cell was able to discharge a total of $\sim 43$ mAh of capacity before the open circuit voltage deviates significantly from the $\mathrm{Li}_{2} \mathrm{O}$ reaction. This is somewhat surprising because the capacity of lithium added to the cell is only $\sim 38 \mathrm{mAh}$. It is unclear if this is a simple mass measurement error, or if the added capacity is due to additional reactions occurring in the cell. In addition, upon attempting to reverse the reaction, the OCV never returns to lithium metal potentials, indicating that lithium metal is not able to be re-deposited once discharged. We suspect that this lack of reversibility is due to the parasitic reduction of the LLZO tube preventing the deposition of lithium metal.

Upon disassembly of the cell, we indeed observe severe blackening of the LLZO tube due to possible reduction reactions either from charging, or simply due to contact with the molten lithium. Photographs of the LLZO tube after the experiment are shown in Figure 5. If the reduced phase of the solid electrolyte is electronically conductive, then the reduction reaction will continue through the entire solid. However, it is also possible that this blackening is due to the chemical reaction alone between the LLZO tube and lithium metal, without applied potential. More detailed examination of the chemical reactions between the LLZO and lithium at high temperatures are 
required to determine the origin of this color change. In addition to the color change in the LLZO tube, a small amount of color change was observed on the YSZ tube. The origin of this color change is less certain, but it may also be due to the low oxygen partial pressure in the tube, as set by the presence of lithium metal on the anode. It may also be due to the molten salt mixture depositing on the tube, which has a different color. Additional experiments are required to understand the degradation of all cell components in this system.

The high fraction of lithium discharged into the system is encouraging, since passivation could have occurred resulting from the discharge products adhering to either of the solid electrolytes. However, the volume fraction of lithium oxide in the molten salt solution was only about $2 \mathrm{~mol} \%$, estimated via mass of salt and lithium metal discharged in the system. For higher amounts of lithium oxide in the salt mixture, additional discharge limitations may appear in the system.
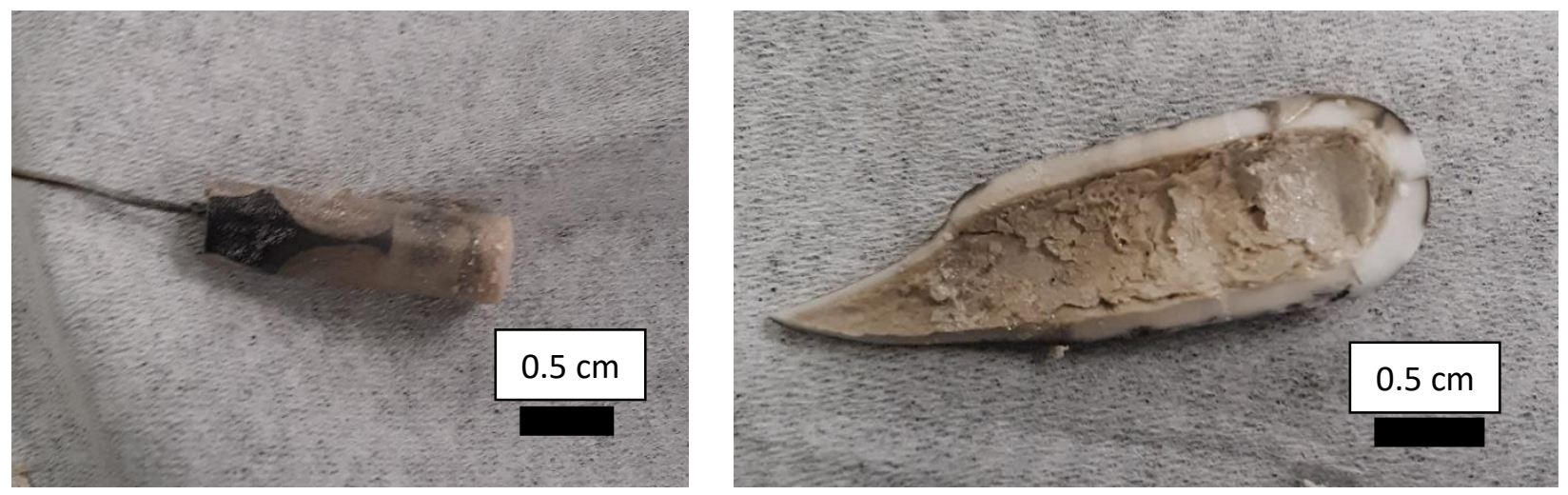

Figure 5: Photographs of LLZO tube (left) and interior of a fragment of YSZ tube (right) after electrochemical tests at $550^{\circ} \mathrm{C}$. Texture seen in the $\mathrm{YSZ}$ tube is a mixture of $\mathrm{LiCl}, \mathrm{KCl}$ and likely a mixture of oxides including $\mathrm{Li}_{2} \mathrm{O}$.

\section{Electrochemical Kinetics}

The discharge of the cell as shown in Figure 4 indicates a significant amount of overpotential in the system. Impedance spectroscopy, shown in Figure 6, in the charged state indicates that there is a significant amount of ohmic resistance in the cell, which likely can be attributed to oxygen conduction through the YSZ tube, and lithium transport through the LLZO tube and molten salt. The low frequency feature is likely from the oxygen reduction reaction on the platinum electrode. Indeed, the cell overpotential during discharge corresponds to a resistance of approximately $65 \mathrm{Ohms}$, significantly lower than the DC resistance implied from the EIS data at open circuit $(\operatorname{Re}(\mathrm{Z})$ as frequency approaches zero), implying a non-linear current-overpotential relationship. In an optimized cell, the platinum electrode will need to be replaced with another oxygen reduction electrode which is more suitable for lower temperature operation. 


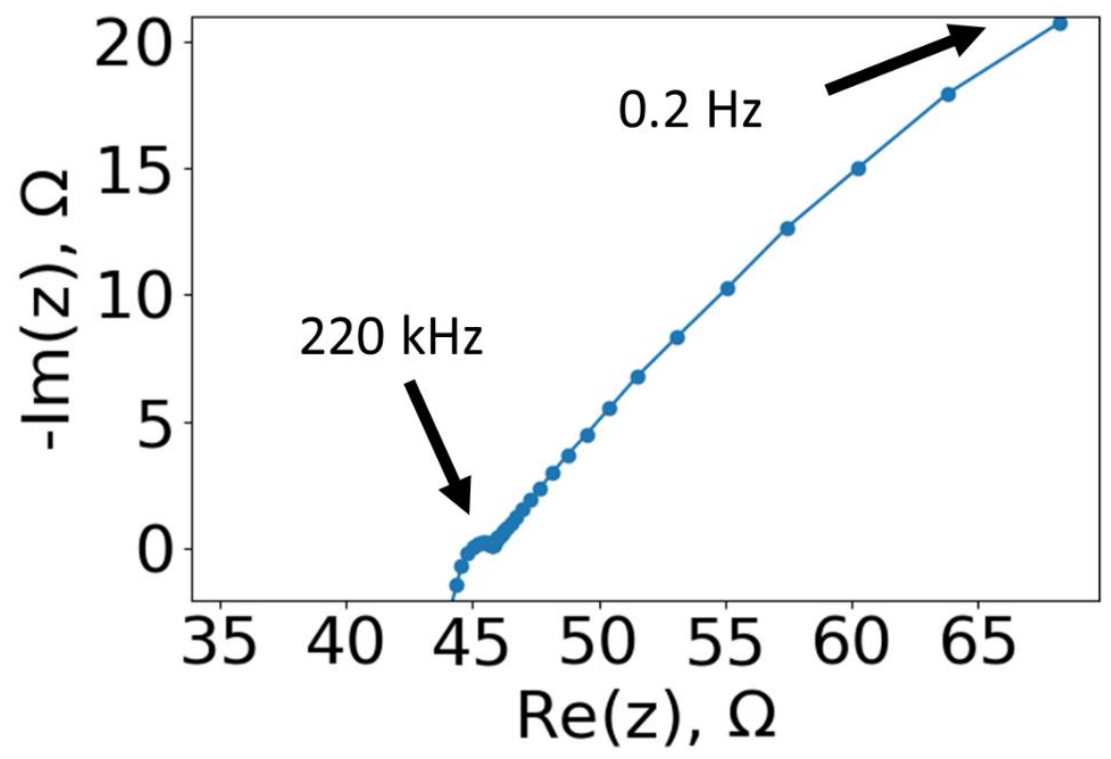

Figure 6: EIS spectra of the $\mathrm{Li}-\mathrm{O}_{2}$ cell at $550^{\circ} \mathrm{C}$ in the charged state

\section{Cell level energy density analysis}

Given that the goal of this architecture is to enable a high energy density, and high specific energy system, a simple cell-level energy density estimate was performed. The detailed parameters of this calculation are included in Figures 7 and 8. If the specific energy goal at the cell level is 1000 $\mathrm{Wh} / \mathrm{kg}$ at the cell level, then there are a possible set of parameters to achieve this goal. Based on optimistic thicknesses of solid electrolyte materials and lithium oxide discharge products, we see that a significant amount of extra mass is available as margin to achieve this specific energy goal. We also calculate the volume breakdown of the system, with a system level goal of $1500 \mathrm{Wh} / \mathrm{L}$, shown in Figure 8. We note that the volumetric energy density is calculated in the charged state, when the system level volume is significantly larger than the discharged state. For comparison, the current state-of-the-art (as of 2021) cell level energy density and specific energy of lithium-ion batteries are about $730 \mathrm{Wh} / \mathrm{L}$ and $265 \mathrm{Wh} / \mathrm{kg}$ respectively.

\section{Mass Breakdown for Li-O2 cell with $1000 \mathrm{Wh} / \mathrm{kg}, 1500 \mathrm{Wh} / \mathrm{L}$}
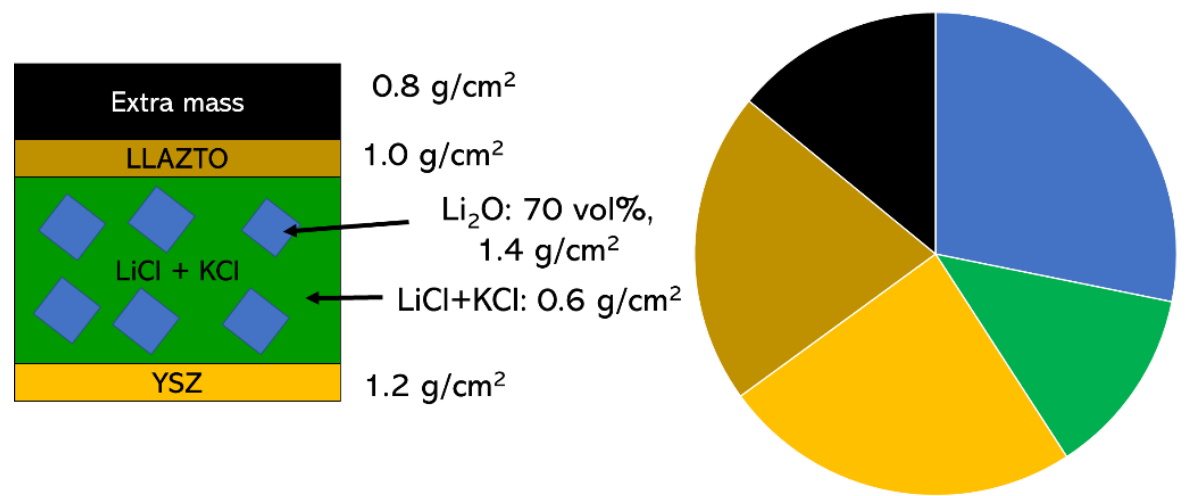

- Lithium oxide

$\mathrm{LiCl}+\mathrm{KCl}$

YSZ

- LLAZTO

- extra

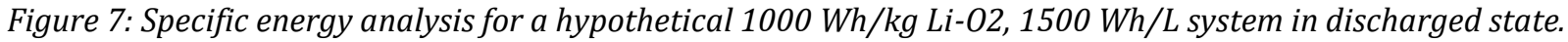
$80 \%$ energy efficiency assumed. For reference, the maximum specific energy of a $\mathrm{Li}^{-} \mathrm{O}_{2}$ system is $4,400 \mathrm{Wh} / \mathrm{kg}$.

System level components are not included in this analysis. 
However, the solid oxide metal air battery analysis does not include the mass and volume of the system-level components such as heating elements, insulation, and fans. Further analysis is needed to examine if the system level specific and volumetric energy density are competitive with state-ofthe-art room temperature battery systems.

As a final aside, from the cell level-analysis we can see that if a high energy density is desired, a large volume fraction of lithium oxide must be present in the molten salt solution. This high volume fraction will result in a significant volume change in the molten salt as the cell charges or discharges. This presents a challenge in terms of power density because the contact area between the molten salt and solid electrolytes will change significantly over the course of charging and discharging the cell.

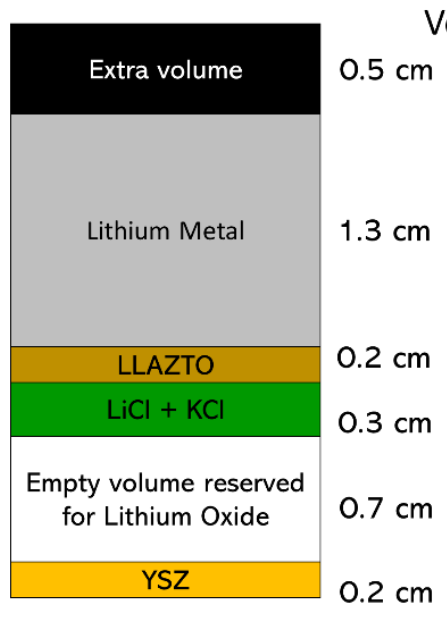

Volume Breakdown for Li-O2 cell with $1000 \mathrm{Wh} / \mathrm{kg}, 1500 \mathrm{Wh} / \mathrm{L}$

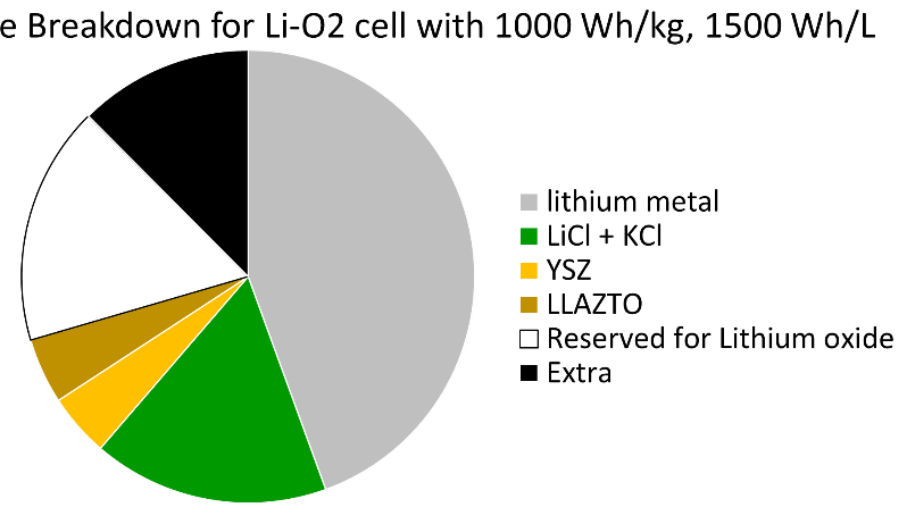

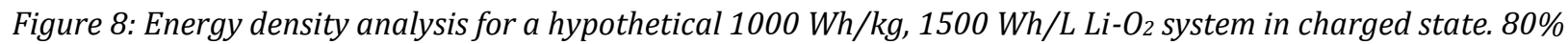
energy efficiency assumed. For reference, the maximum energy density of a Li- $\mathrm{O}_{2}$ system is 10,200 Wh/L. System level components are not included in this analysis

\section{Conclusions}

This work should be considered a first attempt at the construction of a high temperature lithium metal-air battery using a solid oxide fuel cell type architecture on the air electrode. We showed that an open circuit voltage consistent with the $\mathrm{Li}-\mathrm{O}_{2}$ reaction can be obtained, and the cell shows a significant amount of discharge capacity. Unfortunately, we found that if the cell completely discharged, the lithium could not be re-deposited, possibly due to (electro)chemical side reactions with the LLZO tube used in the experiment. In the future, further analysis of the discharge products is needed to confirm the presence of $\mathrm{Li}_{2} \mathrm{O}$ in the molten salt. In addition, it is clear from the color changes in the LLZO tube that significant (electro)chemical reactions are taking place. Future work should seek to design solid electrolyte materials which are either stable to lithium metal at high temperatures, or are coated with a thin layer of a lithium metal stable material. The challenges of operating a lithium metal battery at such high temperatures are significant, but provide an interesting area of further research and may be useful for other fields such as lithium metal electrodeposition. 


\section{Acknowledgements}

G. McConohy is supported by a National Science Foundation Graduate Research Fellowship. This research was partially funded by The Precourt Institute for Energy at Stanford University. We would like to thank Andrey Polatayev, Jason Rugolo, Di Chen, Stephen Kang, and Qiyang Lu for assistance on experimental matters and helpful discussions. We would like to thank Allen Yu-Lun Liang and Devi Ganapathi for helpful comments on the manuscript.

\section{References}

1. Doche, M. L., Novel-Cattin, F., Durand, R. \& Rameau, J. J. Characterization of different grades of aluminum anodes for aluminum/air batteries. Journal of Power Sources 65, 197-205 (1997).

2. Girishkumar, G., McCloskey, B., Luntz, A. C., Swanson, S. \& Wilcke, W. Lithium-Air Battery: Promise and Challenges. J. Phys. Chem. Lett. 1, 2193-2203 (2010).

3. Gallagher, K. G. et al. Quantifying the promise of lithium-air batteries for electric vehicles. Energy Environ. Sci. 7, 1555 (2014).

4. Xia, C., Kwok, C. Y. \& Nazar, L. F. A high-energy-density lithium-oxygen battery based on a reversible four-electron conversion to lithium oxide. Science 361, 777-781 (2018).

5. Giordani, V. et al. A Molten Salt Lithium-Oxygen Battery. J. Am. Chem. Soc. 138, 2656-2663 (2016).

6. Otaegui, L. et al. Performance and stability of a liquid anode high-temperature metal-air battery. Journal of Power Sources 247, 749-755 (2014).

7. Javadekar, A., Jayakumar, A., Gorte, R. J., Vohs, J. M. \& Buttrey, D. J. Energy Storage in Electrochemical Cells with Molten Sb Electrodes. J. Electrochem. Soc. 159, A386-A389 (2012).

8. Ohashi, M. Liquid Aluminum Air Battery Operated at High Temperature. ECS Transactions 58, 75-84 (2014).

9. Semkow, K. W. \& Sammells, A. F. A Lithium Oxygen Secondary Battery. J. Electrochem. Soc. 134, 2084-2085 (1987).

10. Dworkin, A. S., Bronstein, H. R. \& Bredig, M. A. MISCIBILITY OF METALS WITH SALTS. VI. LITHIUM-LITHIUM HALIDE SYSTEMS. J. Phys. Chem. 66, 572-573 (1962).

11. Kado, Y., Goto, T. \& Hagiwara, R. Dissolution Behavior of Lithium Oxide in Molten LiCl-KCl Systems. J. Chem. Eng. Data 53, 2816-2819 (2008). 